\title{
A comparitive study between tranexamic acid and epsilon-amino-caproic acid in reducing post- operative bleeding in patients undergoing on pump cabg surgeries.
}

Rajeev Nair ${ }^{1}$, Satish Kumar Mishra ${ }^{2 *}$, Parli Raghavan Ravi ${ }^{3}$, Avanish Bhardwaj ${ }^{4}$

${ }^{1} \mathrm{MD}$ Anesthesiology HOD Departement of Anesthesiology and critical care Command hospital airforce bangalore

${ }^{2} \mathrm{MD}$, DM Cardiac Anesthesia Departement of Anesthesiology and critical care Command hospital Airforce Bangalore

${ }^{3} \mathrm{MD}$, DNB Anesthesia Departement of Anesthesiology and critical care Command hospital Airforce Bangalore

${ }^{4} \mathrm{MD}$, DM Neuro Anesthesia Departement of Anesthesiology and critical care Command hospital Airforce Bangalore

* Corresponding author: Satish Kumar Mishra, Anesthesiology HOD Departement of Anesthesiology and critical care Command hospital airforce bangalore.

\section{Received date: May 27, 2020; Accepted date: June 09, 2020; Published date: June 12, 2020}

Citation: Rajeev Nair, Satish Kumar Mishra, Parli Raghavan Ravi, Avanish Bhardwaj, (2020) A comparitive study between tranexamic acid and epsilon-amino-caproic acid in reducing post-operative bleeding in patients undergoing on pump cabg surgeries. J Thoracic Disease and Cardiothoracic Surgery, 1(1); DOI: 10.31579/2693-2156/004

Copyright: (c) 2020 Satish Kumar Mishra, This is an open access article distributed under the Creative Commons Attribution License, which permits unrestricted use, distribution, and reproduction in any medium, provided the original work is properly cited.

\section{Abstract}

The amount of strain that cardiac surgery exerts on blood bank services is an example that emphasises the need for multimodel blood conservation stratergy. The most common factor which is being attibutable to increase bleeding after cardiac surgery is hyperfibrinolysis. Thererfore the use of antifibrinolytics during high risk cardiac surgery becomes inevitable. Commonly used antifibrinolytic include Tranexamic Acid(TA) and Epsilon-amino-caproic acid (EACA) .The aim of our study was to compare the effectiveness of both TA and EACA in reducing post-surgical bleeding in on-pump CABG surgeries and to assess the post-operative complications associated with its use.Material and Methods After obtaining informed written consent,approval of ethics and research commitee patients who were scheduled for on-pump CABG were included in the study.Patients were divided into two groups randomly by using a comupter generated randomized block design namely group TA(n=40) and group EACA (n=40). TA group received tranaxamic acid at a dose of $10 \mathrm{mg} / \mathrm{kg}$ IV over $20 \mathrm{~min}$ at the time of induction then $1-2 \mathrm{mg} / \mathrm{kg}$ in CPB prime followed by $1 \mathrm{mg} / \mathrm{kg} / \mathrm{hr}$ infusion during surgery. Group EACA received EACA in a dose of $100 \mathrm{mg} / \mathrm{kg} / \mathrm{IV}$ over 20 min at he time of induction then $5-10 \mathrm{mg} / \mathrm{kg}$ in CPB prime followed by $10 \mathrm{mg} / \mathrm{kg} / \mathrm{hr}$ infusion during surgery . Pateints were assessed for blood loss and were monitored for fibrinogen level and D- dimer levels, Re-exploration and post-operative complications. Result Primary outcomes like bleeding at $4 \mathrm{hrs}$, there was no significant difference between the groups but when total bleeding at 24 hrs was compared therewas a significantly lesser bleed in group TA group compared to group EACA ( $\mathrm{P}=0.0022)$. The requirement of $\mathrm{PRBC}$ in group TA was for 3 patients, where as in EACA group 4 patients required PRBC $(\mathrm{P}>0.05)$. There was no significant difference in the rate of postoperative complications between the groups. $(\mathrm{P}>0.05)$. Conclusion from our study we concluded that both TA \& EACA effectively inhibits fibrinolysis during on pump CABG surgery and thus results in decreased post-operative bleeding. When compared between the two, TA was slightly better with respect to post-operative bleeding at $24 \mathrm{hrs}$.Our study also re emphesized the fact that neither of the drug led to any additional risk of post-operative thrombotic complications .

Key words: TA: Tranexamic Acid; EACA : Epsilon-amino-caproic acid; CPB: Cardio Pulmonary Bypass; PRBC: Packed Red Blood Cell,FFP: Fresh Frozen Plasma

\section{Introduction}

For decades the most common indication for blood transfusion is perioperative bleeding and cardiac surgery ranks high on the list.The reason which is being attributable to this complication is the institution of Cardio Pulmonary Bypass (CPB). CPB leads to series of events like compliment activation, platelet Activation and increased fibrinolysis which contributes to increased post operative bleeding1 .Post operative bleeding in itself carries a high risk for in hospital mortality.Cardiac surgical pateints who are taken up for re explorartion due to bleeding carry a four fold increase in mortality and sternal wound infection 2 . Therfore a multimodal approach is recommended to reduce perioperative bleeding which includes the use of antifibrinolytic agents.

Anti fibrinolytic agents have been used during cardiac surgery to reduce the risk of post operative bleeding. Most commonly used antifibrinolytic agents include Aprotinin and lysine analogs (Tranexamic acid TA and E- amino caproic acid EACA).

Aprotinin is a serine protease inhibitor which inhibits multiple proteases like plasmin, kallikrein, trypsin, and activated factor XII,there by reducing blood loss.in 2007 a prospective study on high risk pateints undergoing cardiac surgery know as Blood conservation using Antifibrinolytics in a Randomized Trial (BART) reported an increased mortality with use of aprotonin compared to lysine analogs 3 . Later due to warning from Food and Drug administration (FDA), Bayer health care withdrew aprotinin from the market.Now the Society of Thoracic Surgeons (STS) guidelines 4 recommend the use of anti-fibrinolytic agents (only lysine analogues), as a strategy to reduce perioperative blood loss during cardiac surgery.

Tranexemic acid (TA) is a synthetic antifibrinolytic that blocks lysine 
binding site on plasminogen molecule, thus inhibiting the interaction with 
plasmin and fibrin which leads to decreased post operative bleeding5-6. Similarly EACA is a synthetic lysin analog which reduces the rate of plasmin formation and further decreases the degradation of fibrin to fibrin degradation product (FDP)7. Apart from this EACA also has a platelet sparing action which leads in inhibition of plasmin mediated platelet injury8.

Both TA and EACA have been shown to decrease post operative bleeding associated with CPB.However there are no large studies comparing the effectiveness of both drugs in pateints undergoing on pump CABG surgeries.

The aim of our study was to compare the effectiveness of both TA and EACA in reducing post surgical bleeding in on-pump CABG surgeries with regards to the amount of blood loss at $4 \mathrm{hrs}$ and $24 \mathrm{hrs}$ as the primary outcome. The secondary outcome of our study included the rate of transfusion of packed red blood cell (PRBC), fresh frozen plasma(FFP) and platelets, re exploration rates,post oprative D-dimer and fibrinogen levels.

\section{Material and Methods}

After obtaining informed written consent,approval of ethics and research commitee patients who were scheduled for on-pump CABG were included in the study. This study was carried out between June 2019 to Feb 2020. Patients with concomitant valvular heart disease, recent Myocardiac Infarction (MI<4wks) Ejection Fraction <40\%, Preexisting neurological,pulmonary or hepatic dysfunction were excluded from the study.

Patients were divided into two groups randomly by using a computer generated randomized block design namely group $\mathrm{TA}(\mathrm{n}=40)$ and group EACA $(n=40)$. In both the group under strict aseptic precaution under local anaesthesia a wide bore peripheral IV cannula,right radial artery cannulation and right femoral artery cannulation was done for continuous hemodynamic monitoring. Anesthesia was induced with Inj etomidate $(0.2 \mathrm{mg} / \mathrm{kg})$, Inj Fentanyl (3-5 ug/ $\mathrm{kg}$ ) and Inj Rocuronium (0.8$1 \mathrm{mg} / \mathrm{Kg}$ ). After induction of patient right internal jugular vein cannulation was done with 7.5 Fr Triple lumen catheter and PA catheter was inserted. Anesthesia was maintained with air and oxygen (50\%), sevoflurane (1-3\%) and Inj Atracurium (0.5-1mg/Kg). After sternotomy and heparinization CPB was established once ACT was $>420$ Sec.

TA group received tranaxamic acid at a dose of $10 \mathrm{mg} / \mathrm{kg}$ IV over $20 \mathrm{~min}$ at the time of induction then $1-2 \mathrm{mg} / \mathrm{kg}$ in CPB prime followed by $1 \mathrm{mg} / \mathrm{kg} / \mathrm{hr}$ infusion during surgery. Group EACA received EACA in a dose of $100 \mathrm{mg} / \mathrm{kg} / \mathrm{IV}$ over $20 \mathrm{~min}$ at he time of induction then $5-10 \mathrm{mg} / \mathrm{kg}$ in CPB prime followed by $10 \mathrm{mg} / \mathrm{kg} / \mathrm{hr}$ infusion during surgery . Later Inj Protamine was administered to reverse the effect of Heparin.

After the completion of surgery patients were shifted to ICU and were assessed for blood loss at $4 \mathrm{hrs}$ and $24 \mathrm{hrs}$ after shifting. Indication for transfusion of PRBC was a haemoglobin level of $<8 \mathrm{gm} / \mathrm{dl}$. FFP was trasfused if post operative drain was $>250 \mathrm{ml} / \mathrm{hr}$ in first hour. Platelet trasfusion was indicated if platelets counts were $<50000 / \mathrm{mm} 3$. The degree of fibrinolysis was measured by Thromboelastography (TEG),(Hemostasis system,Haemoscope corporation USA)

Other parameters which were monitored included fibrinogen level and D- dimer levels at $4 \mathrm{hrs}$ and $24 \mathrm{hrs}$. Re-exploration of case was considered if the bleedng was $>300 \mathrm{ml} / \mathrm{hr}$ in first $2 \mathrm{hrs}$ or if $>200 \mathrm{ml} / \mathrm{hr}$ for 4 cosecutive hrs, with normal coagulation data.Patients were also observed for post operative complications like MI,Stroke,Deep vein thrombosis (DVT),renal dysfunction and seizures for $72 \mathrm{hrs}$.

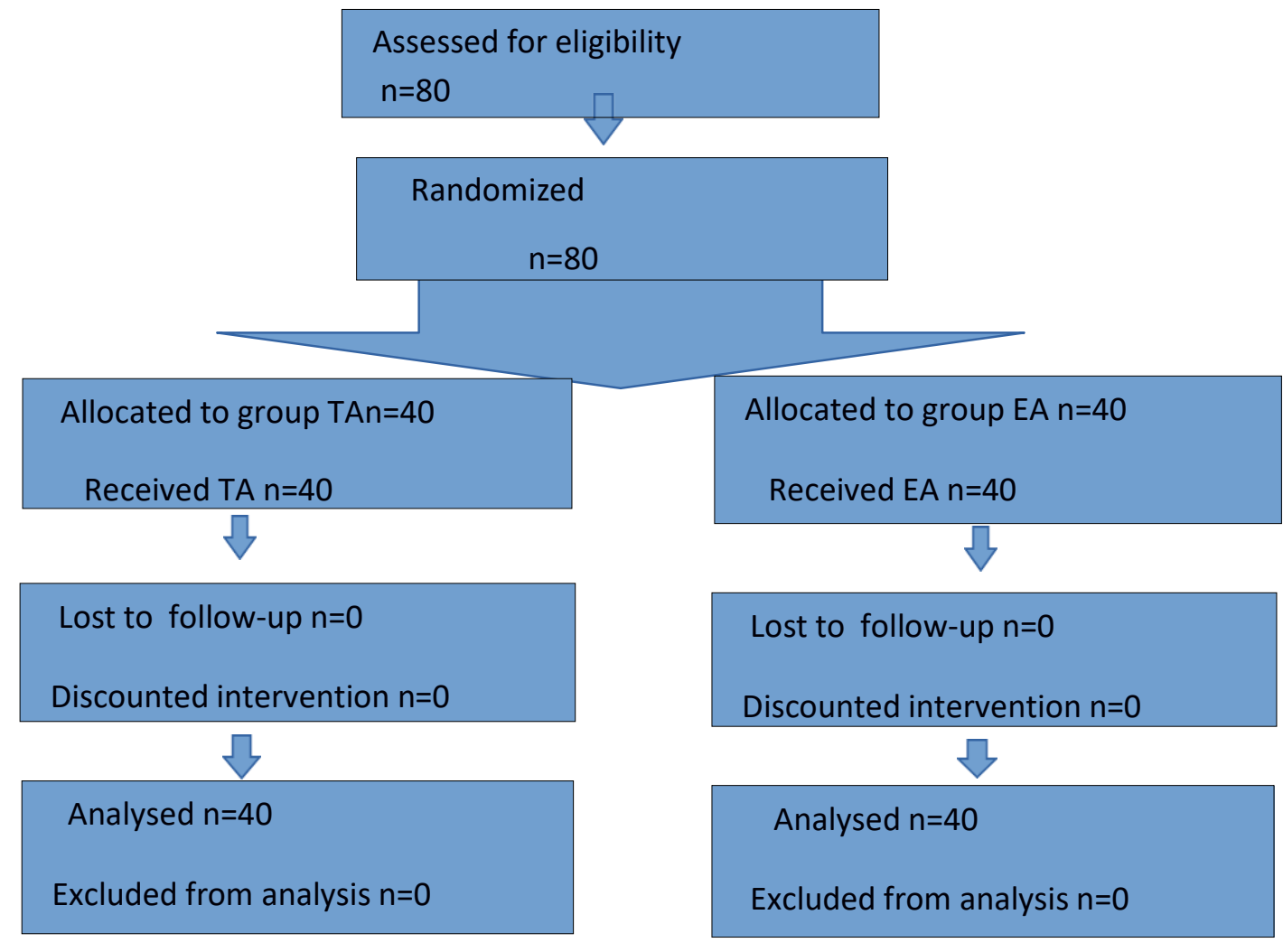

Figure 1: Randomization, group allocation and assessment of patients 


\begin{tabular}{|c|c|c|c|}
\hline Parameter & Group TA $(\mathrm{n}=40)$ & Group EACA(n=40) & P \\
\hline Age $($ Yrs $)$ & $68+/-2$ & $67+/-3$ & 0.967 \\
\hline Weight $(\mathrm{Kg})$ & $74+/-3$ & $76+/-4$ & 0.271 \\
\hline Height $(\mathrm{Cm})$ & $165+/-3$ & $162+/-6$ & 0.118 \\
\hline $\mathrm{M} / \mathrm{F}($ Gender $)$ & $26 / 14$ & $28 / 12$ & 0.739 \\
\hline
\end{tabular}

Table 1. Baseline Demography

\section{TA= Tranexamic Acid EACA= Epsilon-amino-caproic-acid}

\begin{tabular}{|c|c|c|c|}
\hline Variables & Group TA $(\mathrm{n}=40)$ & Group EACA $(\mathrm{n}=40)$ & $\mathrm{P}$ \\
\hline $\begin{array}{c}\text { Cross Clamp } \\
\text { Time }>50 \text { min }\end{array}$ & $10(25 \%)$ & $10(25 \%)$ & 1 \\
\hline CPB $>70$ min & $14(35 \%)$ & $15(37.5 \%)$ & 0.793 \\
\hline
\end{tabular}

Table 2. Inra operative time and intrvention

\begin{tabular}{|c|c|c|c|}
\hline Parameter & Group TA(n=40) & Group EACA(n=40) & P \\
\hline Bleeding at 4hrs $(\mathrm{ml})$ & $190(90-260)$ & $210(110-320)$ & 0.0321 \\
\hline Total Bleeding at 24 hrs $(\mathrm{ml})$ & $360(140-530)$ & $440(170-740)$ & 0.0022 \\
\hline PRBC Transfused & 3 & 2 & 0.921 \\
\hline FFP Transfused & 1 & 1 & 1 \\
\hline Platelet Transfused & 1 & 1 & 1 \\
\hline Re Exploration & 0 & 0 & 1 \\
\hline
\end{tabular}

Table 3. Primary and secondary Outcome

PRBC: Packed Red Blood Cell,FFP: Fresh Frozen Plasma

\begin{tabular}{|c|c|c|c|}
\hline Parameters & Group TA $(n=40)$ & Group EACA(n=40) & P \\
\hline MI & 0 & 1 & 0.981 \\
\hline Stroke & 1 & 1 & 1 \\
\hline Seizure & 1 & 0 & 0.981 \\
\hline PE & 0 & 0 & - \\
\hline DVT & 0 & 0 & 0.981 \\
\hline
\end{tabular}

Table 4. Post-Operative Complications

MI: Myocardial Infarction DVT: Deep Vein Thrombosis PE: Pulmonary Embolism S. Cr: Serum Creatinine.

Statistical analysis was done with SPSS software version 19.0 normality of the test were checked using Kolmogorov-smirnov test. The values which were obtained were analyzed and were expressed as mean +/Standard Deviation (SD) and median $+/$ - range. For continuous variables for parametric data,Indepedent's test were used and for non-parametric data Mann-Whitney u test were used. For categorical data, Chi-Square test or fisher's exact test were used. A P Value of $<0.05$ was considered to be statistically significant.

Result
Demographic variables like age,weight,height, male-female ratio were comparable in both groups. (Table-1) The cross clamp time \& duration on CPB were also comparable in both groups (Table-2). Primary outcomes like bleeding at $4 \mathrm{hrs}$, there was no significant difference between the groups but when total bleeding at $24 \mathrm{hrs}$ was compared there was a significantly lesser bleed in group TA group compared to group $\operatorname{EACA}(\mathrm{P}=0.0022)$.

The requirement of $\mathrm{PRBC}$ in group TA was for 3 patients, where as in EACA group 4 patients required $\mathrm{PRBC}(\mathrm{P}>0.05)$. One pateint in each group required FFP transfusion $(\mathrm{P}>0.05)$. Both the groups did not require any platelet transfusion $\&$ the transfusion rate was non-significantbetween the groups. Both the groups had no re exploration due to excessive bleeding.(Table-3) 
There was no significant difference in the rate of post operative complications between the groups. $(\mathrm{P}>0.05)$ (Table-4)

\section{Discussion}

On pump CABG is associated with increasesd risk of post operative bleeding compared to $\mathrm{OPCAB}^{9-10}$ reason best attributable to use of $\mathrm{CPB}$, which is associated with increased fibrinolysis \& increased concentration of inflammatory mediators, which has urged researchers all around the world to investigate the probable role of antifibrinolytics in on pump cardiac surgeries ${ }^{11}$.

In our study we found that there was no significant difference in the amount of post operative bleeding at 4 hours between the groups however at $24 \mathrm{hrs}$ there was a significant difference between both the groups with lesser bleeding in group TA compared to group EACA. This may be due to the fact the TA is 10 times more potent than $\mathrm{EACA}^{12}$. Similar findings were obtained in a study comparing TA \& EACA with placebo conducted by Karski Et al $^{13}$.

Chauhan Et al ${ }^{14} \&$ Faure Et al ${ }^{15}$ while comparing both the drugs showed that there was no significant difference in the rate of post operative transfusion of PRBC,FFP / Platelet or the rate of re-exploration for excessive bleeding, which was comparable with our study.

Post operative blood transfusion after CABG is associated with increased long term mortality ${ }^{16}$. Therefore the role of these drugs in reducing the transfusion rate after on pump CABG is very significant. There were no difference in the rate of post operative copmlications between the gropus. Hardy Et al in his study while comparing both the drugs did not find any significant difference between the drugs with regards to post operative thrombo embolic complications ${ }^{17}$.

There are controversis with regards to the dosing of the drug .A high dose $(20 \mathrm{mg} / \mathrm{kg})$ TA is associated with increased risk of post operative seizures and therfore a low dose $(10 \mathrm{mg} / \mathrm{kg})$ regiem is recommended ${ }^{18}$.Armelin et al compared the low dose and high dose TA regiem and found no difference with respect to amount of post operative blood loss or transfusion requirement ${ }^{19}$.In our study we used low dose TA dosing and did not find any significant post operative complications.

\section{Conclusion}

Based on the results of our study it can be concluded that both TA \& EACA effectively inhibits fibrinolysis during on pump CABG surgery and thus results in decreased post operative bleeding. When compared between the two, TA was slightly better with respect to post operative bleeding at $24 \mathrm{hrs}$.

Our study also re emphesized the fact that neither of the drug led to any additional risk of post operative thrombotic complications \& thus can potentially become an standard of care for blood conservation in patients undergoing on pump CABG.

\section{References}

1. Paparella D, Galeone A, Venneri MT, Coviello M, Scrascia G, Marraudino N, et al. Activation of the coagulation system during coronary artery bypass grafting operation: Comparison between on pump and off pump techniques. J Thorac Cardiovas Surg 2006;131:290-7.

2. Bridges CR. Valid comparisons of antifibrinolytic agents used in cardiac surgery. Circulation 2007;115:2790-2.

3. Fergusson DA, Hébert PC, Mazer CD, Fremes S, MacAdams C, Murkin JM, Teoh K, Duke PC, Arellano R, Blajchman MA, Bussières JS, Côté D, Karski J, Martineau R, Robblee JA, Rodger M, Wells G, Clinch J, Pretorius R; BART Investigators:
A comparison of aprotinin and lysine analogues in high-risk cardiac surgery. N Engl J Med 2008; 358:2319-31

4. Society of Thoracic Surgeons Blood Conservation Guideline Task Force, Ferraris VA, Brown JR, Despotis GJ, Hammon JW, Reece TB, Saha SP, et al. 2011 Update to The Society of Thoracic Surgeons and the Society of Cardiovascular Anesthesiologists Blood Conservation Clinical Practice Guidelines. Ann Thorac Surg 2011;91:944-82.

5. Mehr-Aein A, Sadeghi M, Madani-civi M. Does tranexamic acid reduce blood loss in off-pump coronary artery bypass? Asian Cardiovasc Thorac Ann 2009;15:285-9.

6. Greilich PE, Jessen ME, Satyanarayana N, Whitten CW, Nuttall GA, Beckham JM et al. The effect of epsilon- aminocaproic acid and aprotinin on fibrinolysis and blood loss in patients undergoing primary, isolated coronary artery bypasssurgery: A randomized, double-blind, placebo-controlled, noninferiority trial. Anesth Analg 2009;109:15-24.

7. Sterns LP, Lillehei CW. Effect of epsilon aminocaproic acid upon blood loss following open-heart surgery: An analysis of 340 patients. Can J Surg 1967;10:304-7.

8. Slaughter TF, Faghih F, Greenberg CS, Leslie JB, Sladen RN. The effects of epsilon-aminocaproic acid on fibrinolysis and thrombin generation during cardiac surgery. Anesth Analg 1997;85:1221-6.

9. Wei M, Jian K, Guo Z, Wang L, Jiang D, Zhang L. Tranexamic acid reduces postoperative bleeding in off-pump coronary artery bypass grafting. Scand Cardiovasc J 2006;40:105-9.

10. Abu-Omar Y, Taggart DP. The present status of off-pump coronary artery bypass grafting. Eur J Cardiothorac Surg 2009;36:312-21.

11. Mariani MA, Gu YJ, Boonstra PW, Grandjean JG, van Oeveren W, Ebels T. Procoagulant activity after off-pump coronary operation: Is the current anticoagulation adequate? Ann Thorac Surg 1999;67:1370-5.

12. Dhir A. Antifibrinolytics in cardiac surgery. Ann Card Anesth 2013;16:117-25.

13. Karski JM, Teasolale SJ, Norma PH, Prevention of post bypass bleeding with tranexamic acid and epsilon aminocaproicacid. J Cardiothorac Vasc Anesth 1993;7:431-5.

14. Chauhan S, Gharde P, Bisoi A, Kale S, Kiran U. A Comparison of aminocaproic acid and tranexamic acid in adult cardiac surgery. Ann Card Anaesth 2004;7:40-3.

15. Falana O, Patel G. Efficacy and safety of tranexamic acid versus aminocaproic acid in cardiovascular surgery. Ann Pharmacother 2014;48:1563-9.

16. Engoren MC, Habib RH, Zacharias A, Schwann TA, Riordan CJ, Durham SJ. Effect of blood transfusion on long-term survival after cardiac operation. Ann Thorac Sure 2002;74:1180-6.

17. Hardy JF, Belisle S, Dupont C, Harel F, Robitaille D, Roy M. Prophylactic tranexemic acid andepsilon aminocaproic acid for primary myocardial revascularization. Ann Thorac Surg 1998;65:371-6.

18. Manji RA, Grocott HP, Leake J, Ariano RE, Manji JS, Menkis $\mathrm{AH}$, et al. Seizures following cardiac surgery: The impact of tranexamic acid and other risk factors. Can J Anest 2012;59:613.

19. Armellin G, Vinciguerra A, Bonato R, Pittarello D, Giron GP. Tranexamic acid in primary CABG surgery: High vs low dose. Minerva Anestesiol 2004;70:97-107 